\title{
Healthcare Staff Perceptions of Patient Safety Culture in Nursing Home Settings- A Cross-Sectional Study
}

\author{
Kathrine Cappelen ${ }^{*}$, Anette Harris ${ }^{2}$, Marianne Storm ${ }^{3}$, Karina Aase ${ }^{3}$ \\ ${ }^{1}$ Center for Care Research South, Faculty of Health and Social Sciences, University College of Southeast Norway, Porsgrunn, \\ Norway \\ ${ }^{2}$ Institute of Psychosocial Science, Faculty of Psychology, University of Bergen, Bergen, Norway \\ ${ }^{3}$ Centre for Resilience in Healthcare, Faculty of Health Sciences, University of Stavanger, Stavanger, Norway \\ Email: *Kathrine.Cappelen@usn.no
}

How to cite this paper: Cappelen, K., Harris, A., Storm, M. and Aase, K. (2017) Healthcare Staff Perceptions of Patient Safety Culture in Nursing Home Settings-A Cross-Sectional Study. Open Journal of Nursing, 7, 1069-1085.

https://doi.org/10.4236/ojn.2017.79078

Received: August 20, 2017

Accepted: September 22, 2017

Published: September 25, 2017

Copyright $\odot 2017$ by authors and Scientific Research Publishing Inc. This work is licensed under the Creative Commons Attribution International License (CC BY 4.0).

http://creativecommons.org/licenses/by/4.0/

\begin{abstract}
In nursing homes, knowledge about patient safety culture is still limited. This study investigates staff perceptions of patient safety culture in Norwegian nursing homes, measured with the Nursing Home Survey on Patient Safety Culture (NHSOPSC). 466 (69\%) staff from 12 different nursing homes participated. The total percentages of positive responses for each patient safety culture dimension and differences in perceptions according to staffs educational background and position were calculated. Multiple linear regression analysis was used to test if the NHSOPSC dimensions predicted participants' ratings of the question "Please give this nursing home an overall rating on patient safety". The proportion of positive responses was high, with six of ten dimensions having an average percentage above 70\%. "Supervisor expectations and actions promoting patient safety" (88\%), "feedback and communication about incidents" (87\%), and a "non-punitive response to mistakes" (78\%) had high average scores, while "staffing" (46\%) and "training and skills" (56\%) had the lowest average scores. Managers reported higher scores on all dimensions, except for "compliance with procedures" compared with other staff groups. Educational level had less influence on staffs perceptions of patient safety culture than management position. The ten NHSOPSC dimensions explained $47.2 \%$ of the variance for the overall rating question "Please give this nursing home an overall rating on patient safety" (F $[10,384]=34.39, p<0.001)$. "Management and organizational learning" had the strongest unique contribution (28.1\%). This study suggests that staff working at the bedside have confidence in their nursing managers' attention to patient safety issues and that a non-punitive environment is prevalent in Norwegian nursing homes.
\end{abstract}




\section{Keywords}

Patient Safety, Safety Culture, Nursing Home, Perceptions, Cross-Sectional Survey

\section{Introduction}

Nursing homes provide complex care to a vulnerable group of patients in terms of age, medically complex conditions, and reduced cognitive function [1] [2]. Increased awareness of patient safety has shown that adverse events related to pressure ulcers, falls, medication, use of physical restraints, and infection outbreaks are common in long-term care (LTC) and nursing home settings [1] [3] [4] [5]. Although the risk of adverse events in nursing homes is prevalent, knowledge of patient safety and patient safety culture is still limited, particularly in Europe, including Scandinavia [6] [7] [8]. A recent Swedish study that described nurses' views on patient safety in nursing homes identified staff competence, sufficient information exchange related to care transitions, continuity of care, and physical work environment as the most influential factors for patient safety in nursing homes [8]. Among barriers were a lack of resources, including competence and staff shortage, and a lack of communication, including internal collaboration and documentation related to patients' transitions. Furthermore, there was a negative attitude to reporting incidents, including a culture of personal blame [8].

Safety culture may be considered as an aspect of organizational culture that refers to how safety is viewed and treated in organizations. Therefore, safety culture can influence behavior and decisions made by healthcare staff at the bedside [9] [10] [11]. Several factors are reported as important for safety culture, such as management support, teamwork, open communication founded on trust, a non-punitive approach to reporting adverse events, and ability to learn and improve [12] [13]. The Agency of Healthcare Research and Quality (AHRQ) refers to the following definition of patient safety culture. "The safety culture of an organization is the product of individual and group values, attitudes, perceptions, competencies, and patterns of behavior that determine the commitment to, and the style and proficiency of, an organization's health and safety management. Organizations with a positive safety culture are characterized by communications founded on mutual trust, by shared perceptions of the importance of safety, and by confidence in the efficacy of preventive measures" ([14]: p. 23). A positive safety culture is known by encouraging honesty, promoting learning, and there is a balance between individual and organizational accountability [15].

Nurses are represented at all organizational levels in nursing homes as strategic policy makers, managers, and clinical staff working directly with patients and are important stakeholders in driving and establishing a culture to support 
patient safety and to ensure the quality of care [2] [16]. The Nursing Home Survey on Patient Safety Culture (NHSOPSC), released in 2008, is specifically designed to measure patient safety culture in nursing homes from a staff perspective [17].

Patient safety culture in primary care, nursing homes and LCT settings have been explored in Sweden [18], Netherlands [7] and recently also in Norway [6]. However, these studies have used adapted or adjusted versions of the Hospital Survey of Patient Safety Culture (HSOPSC) and Safety Attitude Questionnaire (SAQ).

Previous studies among healthcare staff in LTC and nursing home settings from the United States showed that patient safety culture was poorly developed [1] [2] [3]. Fear of reporting adverse events or safety concerns among nursing home staff has been identified as a major barrier to quality improvement [10]. Furthermore, several studies have shown that managers have more positive perceptions of patient safety issues than frontline workers [3] [19] [20], as well as differences in perceptions among different types of nursing home staff [19]. This study aimed to investigate staff perceptions of patient safety culture in Norwegian nursing homes measured with the Norwegian version of NHSOPSC [21].

The specific aims of the study were as follows: 1 ) to examine staff perceptions of patient safety culture in a sample of Norwegian nursing homes as measured by the NHSOPSC; 2) to evaluate differences in staff perceptions of patient safety culture according to educational background and position; and 3) to examine whether some patient safety culture dimensions contribute more to variance than others in the overall rating question: "Please give this nursing home an overall rating on patient safety".

\section{Methods}

\subsection{Design}

We used a cross-sectional design based on the Norwegian version of the AHRQ's NHSOPSC to assess staff perceptions of patient safety culture in a sample of nursing homes [17] [21]. Twelve Norwegian nursing homes from six different municipalities in southern and western Norway representing both urban and rural districts were purposively selected using variation as the main selection criteria. Variation was related to the size of the nursing homes, ranging from one to five wards. Staff participants, according to inclusion criteria, ranged from 15 172 per nursing home. Additionally, the nursing homes differed in how they were organized depending on size, but also related to their level of integration with daycare and home based services. The sample included nursing homes offering specialized care such as long- and short-term care, subacute care, rehabilitation, care for patients with cognitive impairments (such as dementia) and palliative care. Based on the variation criteria the sample of nursing homes included would to a certain extent represent the variety of nursing home settings in Norway. Information regarding the study and the survey instrument were presented 
to nursing home managers as part of the recruitment process. The sample consisted of healthcare staff who were employed in a minimum of $30 \%$ of positions and spoke the Norwegian language. A total of 671 paper-based questionnaires were distributed to study participants between June and September 2013. An information letter followed the questionnaire and participation was based on written informed consent. Each nursing home had a contact person who was responsible for local administration of questionnaires.

\subsection{Study Setting}

Healthcare in Norway is a public responsibility that is mainly financed through taxation and public sources. While the state is responsible for specialized healthcare, such as hospitals, the municipalities are responsible for primary care, including nursing homes. Nursing homes play an important role in the health services system by offering advanced care, including long- and short-term care, sub-acute and acute care, rehabilitation, care for patients with dementia and cognitive impairments, and palliative care [22].

The Norwegian Coordination Reform, which was implemented in 2012, aimed to reduce the need for costly specialized healthcare by transferring medical treatment and nursing tasks from hospitals to nursing homes [23]. Consequently, nursing homes have received an increased number of patients with poor functioning and who are at risk for adverse events. Through the national patient safety program, leadership and safety culture are regarded as crucial aspects for improving patients' safety [24].

\subsection{Questionnaire}

Safety culture was measured with the Norwegian version of the NHSOPSC inventory, which consists of 43 items covering the perceptions of healthcare staff regarding patient safety culture. The original instrument, which comprises 12 factors, has been tested and validated on a large scale in the United States, and is used to examine patient safety culture ratings [17] [19]. When the NHSOPSC inventory was translated and tested in a Norwegian context, results from confirmatory factor analysis showed that a 10-factor model had an acceptable fit in the Norwegian setting as follows: root mean square error of approximation $=$ 0.060 , comparative fit index $=0.934$, Tucker-Lewis index $=0.926, \chi^{2}=2058.33$, degrees of freedom $=765, p<0.001$, and acceptable factor loadings from 0.40 0.89 [21].

All NHSOPSC items are rated on Likert scales from 1 - 5, and include a response alternative "does not apply (DA) or "don't know" (DK). In addition to the 10 dimensions (Table 1), we included one overall rating question considered as outcome as follows: "Please give this nursing home an overall rating on patient safety" (scale from 1 - 5). The survey also collected background demographic variables, such as staff position or background, number of years in a nursing home, work hours per week, work shift, and working directly with patients most of the time [17] [21]. 
Table 1. Description of the 10 dimensions of the Norwegian version of the Nursing Home Survey on Patient Safety Culture instrument.

\begin{tabular}{ll}
\hline $\begin{array}{l}\text { Patients' Safety Culture } \\
\text { Dimensions }\end{array}$ & Description \\
\hline $\begin{array}{l}\text { 1. Teamwork } \\
\text { Staff treat each other with respect, support each other, help } \\
\text { out, and feel they are part of a team } \\
\text { Sufficient staff to cope with the workload, meeting patients' } \\
\text { needs during shift changes, and limited turnover }\end{array}$ \\
$\begin{array}{l}\text { 2. Staffing } \\
\text { 3. Compliance with procedures follow procedures and do not ignore procedures to } \\
\text { make work easier }\end{array}$ \\
$\begin{array}{l}\text { 4. Training and skills } \\
\text { and are trained to deal with complex patients }\end{array}$ \\
$\begin{array}{l}\text { 5. Nonpunitive } \\
\text { response to mistakes }\end{array}$ \\
$\begin{array}{l}\text { Staff are not afraid of reporting mistakes, are not blamed, } \\
\text { and are treated fairly }\end{array}$ \\
$\begin{array}{l}\text { Staff have sufficient knowledge before taking care of a patient and } \\
\text { when a care plan is changed, and they receive sufficient information }\end{array}$ \\
$\begin{array}{l}\text { 7. Feedback and } \\
\text { communication about incidents }\end{array}$ \\
$\begin{array}{l}\text { When staff report harm to patients, the focus is on preventing } \\
\text { 8. Communication openness }\end{array}$ \\
$\begin{array}{l}\text { Staff speak about problems and their ideas are valued } \\
\text { actions promoting patient safetyfeedback, and pay attention to safety problems of patients } \\
\text { 10. Management } \\
\text { and organizational learning }\end{array}$ \\
\hline $\begin{array}{l}\text { Management provides a supportive work environment, } \\
\text { gives safety top priority, and promotes a learning culture }\end{array}$
\end{tabular}

\subsection{Ethics Approval and Consent to Participate}

The study was approved by the Norwegian Social Science Data Services (Ref. No. 2012/32450) and the Norwegian Regional Committees for Medical and Health Research Ethics (Ref. No. 2011/1978). Participation was based on written informed consent.

\subsection{Statistical Analyses}

We used SPSS Version 23.0 (IBM Corporation, Armonk NY, USA) for Windows for the analyses. Average percent positive responses for each of the 10 safety culture dimensions were calculated by averaging the item-level percentage positive responses, when the response alternative DA or DKwas excluded [17]. When the responders answered "strongly agree/agree" and "most of the time/ always" or "strongly disagree/disagree" or "never/rarely" for reverse worded items, the answers were categorized as a positive response. Items with the corresponding mean, standard deviation (SD), number of positive responses per item, percentage of positive responses per item and, average percentage per dimension were reported.

Differences in perception of patient safety culture (10 dimensions) according to educational background and position (managers included leaders at the first-line level, healthcare workers with a minimum of a Bachelor's degree and healthcare workers with upper secondary school education and assistants) were 
tested using one-way, between groups analyses of variance (ANOVA). Assistants included those who responded "assistants" and those who responded "others" related to staff position or background. Separate post-hoc tests (LSD) were conducted for parameters that were significant in the overall analyses.

Multiple linear regression analyses were performed to examine the predictive value of the 10 safety culture dimensions on the outcome question "Please give this nursing home an overall rating on patient safety". All of the independent variables were entered simultaneously. Pearson's Product-Moment Correlation and preliminary analyses were conducted to ensure no violation of the assumptions of normality, linearity, multicollinearity, and homoscedasticity before we performed the regression analyses. No violation was found and the correlation coefficients varied between 0.236 and 0.635 . The unstandardized coefficient (B), standard error of the mean (SE), standardized beta coefficient $(\beta)$, and the unique predictive contribution for each of the dimensions $\left(s r^{2}{ }_{\text {unique }}\right)$ are presented. A $p$ value of $<0.005$ was regarded as significant.

\section{Results}

\subsection{Descriptive Statistics}

A total of 466 healthcare staff responded to the questionnaire, with a response rate of $69 \%$. The participants were representative for Norwegian nursing home staff and 6.3\% included managers, comprising leaders at first line level $(n=29)$, $39.6 \%$ were healthcare workers with a minimum of a Bachelor's degree ( $\mathrm{n}=$ 181 ), and $54 \%$ were healthcare workers with upper secondary school education and assistants, $(\mathrm{n}=247)$. Furthermore, $45.7 \%$ of the staff reported working $>10$ years in the nursing home $(\mathrm{n}=209), 71.8 \%$ reported work hours $>25$ per week $(\mathrm{n}=326), 67.7 \%$ worked in the daytime most often $(\mathrm{n}=303)$, and $95.2 \%$ of the respondents working directly with patients most of the time $(n=436)$.

\subsection{Perceptions of Patient Safety Culture in Norwegian Nursing Homes}

The proportion of positive responses was high. Six of the 10 dimensions had an average percentage of positive responses above $70 \%$ (Table 2). The dimensions with the highest percentages were "supervisor expectations and actions promoting patient safety" (88\%) and "feedback and communication about incidents" (87\%). "Non-punitive response to mistakes" also showed a high score (78\%). The dimensions with the lowest percentages were "staffing" (46\%) and "training and skills" (56\%). Moreover, $80.9 \%$ of respondents rated the overall patient safety grade in their nursing home as excellent or very good, $17.4 \%$ as acceptable, and $1.8 \%$ as fair $(\mathrm{n}=449)$.

\subsection{Perception of Patient Safety Culture According to Educational Background and Position}

Managers, including leaders at the first-line level, reported higher scores in all of the dimensions, except for "compliance with procedures" compared with the 
Table 2. Items with the corresponding mean (SD), number of positive responses, percentage of positive responses per item and per dimension.

\begin{tabular}{|c|c|c|c|}
\hline $\begin{array}{l}\text { Patient Safety } \\
\text { Culture } \\
\text { Dimensions }\end{array}$ & Items & Mean (SD) & $\begin{array}{l}\text { Positive responses } \\
\text { ) per item } \\
\text { (percentages) }\end{array}$ \\
\hline \multirow[t]{5}{*}{ 1. Teamwork } & $\begin{array}{l}\text { A1. Staff in this nursing home treat each } \\
\text { other with respect }\end{array}$ & $4.31(0.79)$ & $392(85 \%)$ \\
\hline & A2. Staff support one another in this nursing home & e $4.18(0.79)$ & $369(80 \%)$ \\
\hline & A5. Staff feel like they are part of a team & $4.10(0.82)$ & $372(80 \%)$ \\
\hline & $\begin{array}{l}\text { A9. When someone gets really busy in } \\
\text { this nursing home, other staff help out }\end{array}$ & $3.71(0.85)$ & $276(60 \%)$ \\
\hline & & & $76 \%^{1}$ \\
\hline \multirow[t]{6}{*}{ 2. Staffing } & A3. We have enough staff to handle the workload & $2.97(0.89)$ & $110(24 \%)$ \\
\hline & $\begin{array}{l}\text { A8 (R). Staff have to hurry because } \\
\text { they have too much work to do }\end{array}$ & $2.55(0.92)$ & $51(11 \%)$ \\
\hline & A16. Patients needs are met during shift changes & $3.80(0.81)$ & $295(66 \%)$ \\
\hline & $\begin{array}{l}\text { A17 (R). It is hard to keep patients safe } \\
\text { here because so many staff quit their jobs }\end{array}$ & $4.11(0.85)$ & $355(83 \%)$ \\
\hline & & & $46 \%^{1}$ \\
\hline & 3. Compliance withto care for patients & $4.00(0.79)$ & $353(78 \%)$ \\
\hline procedures & $\begin{array}{l}\text { A6 (R). Staff use shortcuts to get their } \\
\text { work done faster }\end{array}$ & $3.38(0.92)$ & $206(46 \%)$ \\
\hline & $\begin{array}{l}\text { A14 (R). To make work easier, } \\
\text { staff often ignore procedures }\end{array}$ & $3.82(0.81)$ & $312(70 \%)$ \\
\hline & & & $65 \%^{1}$ \\
\hline \multirow{4}{*}{$\begin{array}{l}\text { 4. Training and } \\
\text { skills }\end{array}$} & $\begin{array}{l}\text { A7. Staff get the training they need } \\
\text { in this nursing home }\end{array}$ & $3.63(0.86)$ & $264(57 \%)$ \\
\hline & $\begin{array}{l}\text { A11. Staff have enough training on } \\
\text { how to handle difficult patients }\end{array}$ & $3.21(0.86)$ & $153(34 \%)$ \\
\hline & $\begin{array}{l}\text { A13. Staff understand the training } \\
\text { they get in this nursing home }\end{array}$ & $3.89(0.73)$ & $332(76 \%)$ \\
\hline & & & $56 \%^{1}$ \\
\hline \multirow{5}{*}{$\begin{array}{l}\text { 5. Nonpunitive } \\
\text { response to } \\
\text { mistakes }\end{array}$} & A10 (R). Staff are blamed when a patient is harmed & d $4.13(0.77)$ & $372(87 \%)$ \\
\hline & A12 (R). Staff are afraid to report their mistakes & $3.76(0.83)$ & $291(67 \%)$ \\
\hline & $\begin{array}{l}\text { A15. Staff are treated fairly when they make mis- } \\
\text { takes }\end{array}$ & $3.95(0.79)$ & $333(80 \%)$ \\
\hline & A18. Staff feel safe reporting their mistakes & $3.97(0.74)$ & $347(78 \%)$ \\
\hline & & & $78 \%^{1}$ \\
\hline \multirow[t]{4}{*}{ 6. Handoffs } & $\begin{array}{l}\text { B1. Staff are told what they need to know before } \\
\text { taking care of a patient for the first time }\end{array}$ & $4.01(0.72)$ & $367(80 \%)$ \\
\hline & $\begin{array}{l}\text { B2.Staff are told right away when there } \\
\text { is a change in a patient's care plan }\end{array}$ & $3.79(0.78)$ & $308(69 \%)$ \\
\hline & $\begin{array}{l}\text { B10. Staff are given all the information } \\
\text { they need to care for patients }\end{array}$ & $4.24(0.63)$ & $417(91 \%)$ \\
\hline & & & $80 \%^{1}$ \\
\hline
\end{tabular}




\section{Continued}

7. Feedback and communication about incidents

B4. When staff report something that could harm a patient, someone takes care of it

B5. In this nursing home, we talk about ways to keep incidents from happening again $3.98(0.78) 358(79 \%)$

B6. Staff tell someone if they see something that might harm a patient

$4.42(0.58) 436(96 \%)$

B8. In this nursing home, we discuss ways to keep patients safe from harm

$4.07(0.69) 381(85 \%)$

$87 \%^{1}$

8. Communication B7. Staff ideas and suggestions are openness valued in this nursing home

$3.85(0.74) 329(72 \%)$

B9 (R). Staff opinions are ignored in this nursing home

$3.82(0.83) 317(71 \%)$

B11. It is easy for staff to speak up about problems in this nursing home

$3.90(0.85) 316(71 \%)$

$71 \%$

9. Supervisor

C1. My supervisor listens to staff ideas and expectations and suggestions about patient safety

$.22(0.76) 381(84 \%)$

actions promoting $\mathrm{C} 2$. My supervisor says a good word to patient safety staff who follow the right procedures

C3. My supervisor pays attention to patient safety problems in this nursing home
$4.19(0.78) 388(86 \%)$

$4.38(0.66) 419(93 \%)$

$88 \%^{1}$

D1. Patients are well cared for in this nursing home4.33 (0.73) 411 (89\%)

10. Management D2. Management asks staff how the nursing and organizational home can improve patient safety

learning

D3 (R). This nursing home lets the same mistakes happen again and again

$3.70(0.85) 282(65 \%)$

D4. It is easy to make changes to improve patient safety in this nursing home

D5. This nursing home is always doing things to improve the patient safety

D6. This nursing home does a good job keeping patients safe

D7. Management listens to staff ideas and suggestions to improve patient safety

$3.80(0.83) 300(68 \%)$

D8. This nursing home is a safe place for patients $4.30(0.64) 418(91 \%)$

D9. Management often walks around the nursing home to check on patient care

D10. When this nursing home makes changes to

improve patient safety, it checks to see

$3.61(0.84) 221(61 \%$

if the changes worked

$67 \%^{1}$

Notes: $\mathrm{R}$ = reverse coded items. Positive responses were defined as answering "strongly agree/agree" and "most of the time/always" or "strongly disagree/disagree or "never/rarely" for reversed coded items. ${ }^{1}$ Average percentage of positive responses per dimension. A, B, C and D representing sections in the questionnaire. 
two other staff groups (Table 3). With regard to educational level, healthcare workers with upper secondary school and assistants reported higher scores on two dimensions, "handoffs" and "management and organizational learning", compared with healthcare workers with a minimum of a Bachelor's degree.

\subsection{Perception of Patient Safety Culture and the Overall Rating of Patient Safety}

Standard multiple linear regression analysis showed that the 10 NHSOPSC dimensions explained $47.2 \%$ of the variance for the outcome question "Please give this nursing home an overall rating on patient safety" (F [10,384] $=34.39, p<$ 0.001) (Table 4). Only three dimensions ("staffing", "handoffs," and "management and organizational learning") made unique significant contributions to the model when the overlapping effects of all other variables were removed. "Management and organizational learning" made the strongest unique contribution to the model and explained $28.1 \%$ of the variance for the outcome question "Please give this nursing home an overall rating on patient safety".

Table 3. Comparison of patient safety culture scores across managers, including leaders at the first-line level, healthcare workers with a minimum of a Bachelor's degree, and healthcare workers with upper secondary school education and assistants.

\begin{tabular}{|c|c|c|c|c|}
\hline \multirow[b]{2}{*}{$\begin{array}{l}\text { Patient Safety Culture } \\
\text { Dimensions }\end{array}$} & \multicolumn{4}{|c|}{ Staff groups } \\
\hline & Managers & $\begin{array}{l}\text { Bachelor's } \\
\text { degree }\end{array}$ & $\begin{array}{l}\text { Upper } \\
\text { secondary } \\
\text { school } \\
\text { education/ } \\
\text { assistants }\end{array}$ & $F(d f), p$ value \\
\hline & Mean (SD) & Mean (SD) & Mean (SD) & \\
\hline 1. Teamwork & $4.33(0.34)$ & $4.04(0.61)$ & $4.04(0.67)$ & $2.94(2,450)=0.06^{\mathrm{a}, \mathrm{b}^{*}}$ \\
\hline 2. Staffing & $3.56(0.62)$ & $3.25(0.70)$ & $3.24(0.59)$ & $3.24(2,444)=0.04^{\mathrm{a}, \mathrm{b}^{*}}$ \\
\hline 3. Compliance with procedures & $3.78(0.60)$ & $3.64(0.69)$ & $3.620 .71)$ & $0.70(2,447)=0.50$ \\
\hline 4. Training and skills & $3.77(0.61)$ & $3.36(0.71)$ & $3.53(0.70)$ & $5.52(2,448)<0.01^{\mathrm{a}^{* *}, \mathrm{~b}^{*}}$ \\
\hline $\begin{array}{l}\text { 5. Nonpunitive response to } \\
\text { mistakes }\end{array}$ & $4.07(0.84)$ & $3.77(0.72)$ & $3.75(0.72)$ & $2.49(2,437)=0.08^{\mathrm{a}, \mathrm{b}^{*}}$ \\
\hline 6. Handoffs & $4.33(0.53)$ & $3.85(0.66)$ & $4.00(0.61)$ & $8.37(2,446)<0.01^{\mathrm{a}, \mathrm{b}^{* *}, \mathrm{c}^{*}}$ \\
\hline $\begin{array}{l}\text { 7. Feedback and communication } \\
\text { about incidents }\end{array}$ & $\mathrm{n}_{4.40}(0.42)$ & $4.04(0.64)$ & $4.13(0.60)$ & $4.94(2,439)<0.01^{\mathrm{a}^{* *}, \mathrm{~b}^{*}}$ \\
\hline 8. Communication openness & $4.30(0.48)$ & $3.78(0.72)$ & $3.76(0.69)$ & $7.97(2,445)<0.01^{\mathrm{a}, \mathrm{b}^{* *}}$ \\
\hline $\begin{array}{l}\text { 9. Supervisor expectations and } \\
\text { actions promoting patient safety }\end{array}$ & $y=2.23(0.54)$ & $4.21(0.73)$ & $4.23(0.68)$ & $0.03(2,444)=0.97^{\mathrm{a}, \mathrm{b}^{* *}}$ \\
\hline $\begin{array}{l}\text { 10. Management } \\
\text { and organizational learning }\end{array}$ & $3.98(0.52)$ & $3.53(0.64)$ & $3.67(0.62)$ & $7.10(2,427)<0.01^{a, b^{* *}, c^{*}}$ \\
\hline
\end{tabular}


Table 4. The predictive values of the 10 patient safety culture dimensions on the overall rating question, "Please give this nursing home an overall rating on patient safety".

\begin{tabular}{|c|c|c|c|c|}
\hline \multirow{2}{*}{$\begin{array}{l}\text { Patients' Safety Culture } \\
\text { Dimensions }\end{array}$} & \multicolumn{4}{|c|}{ Overall rating on patient safety } \\
\hline & B & SE & $\beta$ & $s r^{2}$ (unique) \\
\hline 1. Teamwork & 0.012 & 0.013 & 0.045 & 0.036 \\
\hline 2. Staffing & 0.027 & 0.013 & $0.094^{*}$ & 0.079 \\
\hline 3. Compliance with procedures & 0.024 & 0.016 & 0.067 & 0.055 \\
\hline 4. Training and skills & -0.007 & 0.017 & -0.019 & -0.015 \\
\hline $\begin{array}{l}\text { 5. Nonpunitive response to } \\
\text { mistakes }\end{array}$ & 0.011 & 0.011 & 0.042 & 0.035 \\
\hline 6. Handoffs & 0.045 & 0.019 & $0.114^{*}$ & 0.088 \\
\hline $\begin{array}{l}\text { 7. Feedback and communication } \\
\text { about incidents }\end{array}$ & 0.021 & 0.016 & 0.065 & 0.050 \\
\hline 8. Communication openness & 0.022 & 0.018 & 0.062 & 0.044 \\
\hline $\begin{array}{l}\text { 9. Supervisor expectations and } \\
\text { actions promoting patient safety }\end{array}$ & 0.009 & 0.017 & 0.025 & 0.020 \\
\hline $\begin{array}{l}\text { 10. Management } \\
\text { and organizational learning }\end{array}$ & 0.047 & 0.006 & $0.408^{* *}$ & 0.281 \\
\hline $\mathrm{R}^{2}$ & 0.472 & & & \\
\hline Adjusted $\mathrm{R}^{2}$ & 0.459 & & & \\
\hline
\end{tabular}

\section{Discussion}

\subsection{Perceptions of Patient Safety Culture}

This study is the first using the NHSOPSC in a cross-sectional design to report how a sample of healthcare staff in 12 Norwegian nursing homes perceive patient safety culture. Our study showed a positive awareness of patient safety culture among nursing home staff. Frequently cited dimensions related to safety culture, such as "leadership commitment to safety", "non-punitive response to mistakes", "teamwork", and "communication openness", had a high percentage of positive responses [13]. To some extent, these findings contradict previous studies indicating that patient safety culture is poorly developed in nursing homes and LTC settings, including a recent Norwegian study [1] [2] [3] [6].

Our study supports Castle et al.'s study that compared safety culture in nursing homes and hospitals in the US using respectively the NHSOPSC and the HSOPSC [25]. They found that nursing home scores were generally better when comparing similar items in the HSOPSC questionnaire. Out of 26 highly similar items in the questionnaires, 16 of the NHSOPSC scores were higher than the HSOPSC scores. These results from US were not confirmed in a study from $\mathrm{Ne}-$ therland where patient safety culture in nursing homes, measured with SAQ, were comparable to those found in Dutch and US Intensive Care Units and ambulatory services [7]. Due to the scarcity of studies from European nursing home context using the NHSOPSC, cautions should be made when comparing studies 
having used different assessment tools.

In our study, the dimensions "supervisor expectations and actions promoting patient safety" (88\%) and "feedback and communication about incidents" (87\%) showed the highest percentages of positive responses. These results indicate that staff working at the bedside in Norwegian nursing homes have confidence in their frontline nursing managers. Engaged nursing managers listening to frontline staff's concerns and promoting improvement of patient safety can serve as important role models in nursing homes. A recent Danish study investigated staff's perceptions of patient safety culture before and after a leadership intervention [26]. This Danish study showed that strengthening leadership could act as a catalyst for improvement in the proportion of staff with positive attitudes and a more positive safety culture.

Fear of reporting has been recognized as a barrier to improvement in safety nursing homes [10]. Data from the AHRQ Comparative Database Report 2016 still found "non-punitive response to mistakes" among the dimensions that had the lowest average percentage of positive responses (54\%) [27] [28]. In contrast, our study showed that "non-punitive response to mistakes" had a high average percentage of positive responses (78\%). This finding indicates that staff feel confident in reporting safety concerns. Furthermore, teamwork, identified in the literature as the second most critical sub-dimension of patient safety culture, after leadership, showed a high average percentage of positive responses in our study (76\%) [12]. Norwegian work life is characterized by a democratic leadership style and staff involvement in decision-making [29]. Additionally, national patient safety initiatives and legislation have shifted from focusing on the person to focusing on the system [24]. Notably, we found that "communication openness" had a slightly lower average percentage of positive responses $(71 \%)$ than "nonpunitive response to mistakes" (78\%) and "teamwork" (76\%). This is in line with a Swedish study that described nurses' views on safety in nursing homes, and identified lack of communication and negative attitudes to reporting incidents among profound patient safety barriers [8].

Our results for the dimensions "staffing" and "training and skills" are of concern because they had the lowest percentages of positive responses. Simultaneously, there has been steady growth of older patients with multiple diagnoses who are discharged from hospitals to primary care services, including nursing homes [30]. A recent study among municipality healthcare nurses in Norway concluded that the majority of nurses experienced complex and challenging work, but they lacked time, competencies, equipment, and information to sufficiently care for their patients [30]. Staffing appears to be a common challenge in nursing homes, exacerbated by financial issues and a lack of skilled staff and training [2] [30] [31]. A study that compared nursing home staffing standards in six countries showed wide variations within and across countries [16]. The increasing levels of severity of illness among patients in nursing homes highlights the need for further attention to staffing standards, to assure the quality of care. 
Norway has no official standards for staffing in nursing homes [31]. Staff training is an important aspect of safety improvement, but may be challenged by work shift arrangements and insufficient staffing levels.

\subsection{Educational Background and Position}

The respondents in the current study were considered representative for nursing home staff and nearly all of them (95.2\%) worked directly with patients most of the time. In our study sample, we found that managers, including leaders at the first-line level, reported higher scores on all the dimensions, except for "compliance with procedures", compared with the two other staff groups (healthcare workers with a minimum of a Bachelor's degree and healthcare workers with upper secondary school education and assistants). This finding is in line with previous studies, which reported that managers have significantly more positive safety culture perceptions than do frontline staff [3] [19] [20]. Comparison with other European studies is not possible as they lack management position in background characteristics" [6] [7].

Educational level appeared to have less influence on staff's perceptions of patient safety culture than management position. Still, we found that healthcare workers with upper secondary school education and assistants reported higher scores in the two dimensions "handoffs" and "management and organizational learning" than did healthcare workers with a minimum of a Bachelor's degree. These results are in line with a Dutch study using SAQ reporting a negative correlation between education and safety climate [7]. The SAQ factor safety climate seems to some extend have similarity to the management and organizational learning dimension in the Norwegian NHSOPSC. Lower scores among staff with a minimum of a Bachelor's degree might be a result of higher clinical competence and clinical assessment ability. However, the results to some extend contradictory to the findings of a recent Norwegian study where neither profession nor work experience were significantly associated with mean scores for any patient safety factor [6]. This inconsistency in results might be explained by study samples and should be further investigated.

\subsection{Overall Rating on Patient Safety}

The present study showed that the "management and organizational learning" dimension was the strongest unique contributor to the outcome question related to overall staff ratings on patient safety. This dimension consists of 10 items, including management support, safety priority, learning systems, and improvement changes. Considering that organizational characteristics are a stronger predictor of safety culture than individual behavior, changes toward an improved patient safety culture in nursing homes should be performed at an organizational level [10]. Management support means putting patient safety issues on the strategic agenda. Staff in nursing homes should know that they are not held accountable for system failures. Learning systems should be able to capture 
information and concerns from the frontline staff, besides having the capacity to drive improvement. The patient safety factor "perceptions of management" including managements support of daily efforts seems not to be included in the Norwegian version of SAQ for nursing homes [6]. Comparison is therefore not possible. Hence, previous studies have suggested a need for leadership involvement at all organizational levels and highlight managers' responsibility in establishing and sustaining safety culture as a key driver in patient safety work [24] [26] [32].

\subsection{Strengths and Limitations}

A strength of the present study is the response rate of $69 \%$, which can be partly explained by the substantial leadership involvement in recruitment and feedback of results. The high number of respondents working directly with patients (including day, afternoon, and night shifts) provided important information from frontline staff on patient safety culture in nursing homes. Respondents included staff with relatively high levels of education and low rates of turnover, which are considered important to patient safety.

Twelve nursing homes located in the southwest region of Norway were included in the study based on their interest in patient safety issues and by actively enrolling in the study. Although our study results are not necessarily generalizable to all nursing homes in Norway, they provide a valuable overview of the patient safety culture across a number of nursing homes. Some of the nursing homes in our sample also participated in the Norwegian Patient Safety Campaign, adding explanatory value to the high percentages of positive responses.

One limitation of this study is the low number of managers participating in the study $(n=29)$. Another important limitation is the lack of an objective outcome that measures patient safety (e.g., falls and medication errors). Therefore, we had to relate to the subjective overall rating question "Please give this nursing home an overall rating on patient safety".

\subsection{Conclusions}

Assessing patient safety culture can be the first step in identifying areas of improvement and barriers to provide safe care. We found a positive awareness of patient safety culture among frontline staff in participating Norwegian nursing homes. The highest proportion of positive responses was for the dimension "supervisor expectations and actions promoting patient safety," indicating that staff have confidence in their frontline nursing managers. Furthermore, "feedback and communications about incidents" and "non-punitive response to mistakes" had high scores. Fear of reporting mistakes is considered a major barrier to improvement in safety. Areas of particular concern were staff perceptions of the "staffing" and "training and skills" dimensions, especially considering the increasing transfer of medical treatment and complex nursing tasks from hospitals to nursing homes. 
As expected, managers reported higher scores on all dimensions, except for "compliance with procedures", compared with other staff groups, while educational level had less effect on staff's perceptions of patient safety culture. "Management and organizational learning" made the strongest unique contribution to overall staff ratings of patients' safety, indicating the importance of actions taken at an organizational level to support a robust safety culture. Further research should include objective outcomes that measure patient safety, such as falls and medication errors, to identify if improvement in safety culture affects clinical outcomes. Culture assessments may increase the awareness of safety issues and support quality improvement initiatives.

\section{Acknowledgements}

The authors would like to thank management and staff of the participating nursing homes for assistance in collection of data, and Nina Konglevoll for technical assistance. We thank Ellen Knapp, $\mathrm{PhD}$, from Edanz Group for editing a draft of this manuscript.

\section{Competing Interests}

The authors declare that they have no competing interests.

\section{Authors' Contributions}

$\mathrm{KC}$ was responsible for designing the study, developing the Norwegian version of the NHSOPSC, data collection, statistical analysis, interpretation of data, and writing the first draft of the manuscript. AH contributed to interpretation of the data and revision of the manuscript. MS participated in data collection and revision of the manuscript. KA supervised the design of the study, contributed to interpretation of data, and critically revised the manuscript. All authors read and approved the final manuscript.

\section{Funding}

The study received funding from the Norwegian Nurses Organization and the Norwegian Research Council (grant agreement No. 204637). The funders had no part in the design of the study, the collection, analysis, and interpretation of data, or in writing the manuscript.

\section{References}

[1] Thomas, K.S., Hyer, K., Castle, N.G., Branch, L.G., Andel, R. and Weech-Maldonado, R. (2012) Patient Safety Culture and the Association with Safe Resident Care in Nursing Homes. Gerontologist, 52, 802-811. https://doi.org/10.1093/geront/gns007

[2] Bonner, A.F., Castle, N.G., Perera, S. and Handler, S.M. (2008) Patient Safety Culture: A Review of the Nursing Home Literature and Recommendations for Practice. Annals of Long-Term Care, 16, 18-22.

[3] Wagner, L.M., Capezuti, E. and Rice, J.C. (2009) Nurses' Perceptions of Safety Cul- 
ture in Long-Term Care Settings. Journal of Nursing Scholarship, 41, 184-192. https://doi.org/10.1111/j.1547-5069.2009.01270.x

[4] Zúñiga, F., Schwappach, D., De Geest, S. and Schwendimann, R. (2013) Psychometricproperties of the Swiss Version of the Nursing Home Survey on Patient Safety Culture. Saf Sci.

[5] Wagner, L.M. (2016) Improving the Patient Safety Culture in Nursing Homes through Walk Rounds. The Joint Commission Journal on Quality and Patient Safety, 42, 543-544. https://doi.org/10.1016/S1553-7250(16)30105-2

[6] Bondevik, G.T., Hofoss, D., Husebø, B.S. and Deilkås, E.C.T. (2017) Patient Safety Culture in Norwegian Nursing Homes. BMC Health Services Research, 17, 424.

https://doi.org/10.1186/s12913-017-2387-9

[7] Buljac-Samardzic, M., van Wijngaarden, J.D. and Dekker-van Doorn, C.M. (2015) Safety Culture in Long-Term Care: A Cross-Sectional Analysis of the Safety Attitudes Questionnaire in Nursing and Residential Homes in the Netherlands. BMJ Quality \& Safety, 25, 424-431. https://doi.org/10.1136/bmjqs-2014-003397

[8] Andersson, F. and Hjelm, K. (2017) Patient Safety in Nursing Homes in Sweden: Nurses' Views on Safety and their Role. Journal of Health Services Research \& Policy, 1355819617691070. https://doi.org/10.1177/1355819617691070

[9] Nordin, A., Theander, K., Wilde-Larson, B. and Nordström, G. (2013) Health Care Staffs' Perception of Patient Safety Culture in Hospital Settings and Factors of Importance for This. Open Journal of Nursing, 3, 28-40. https://doi.org/10.4236/ojn.2013.38A005

[10] Arnetz, J.E., Zhdanova, L.S., Elsouhag, D., Lichtenberg, P., Luborsky, M.R. and Arnetz, B.B. (2011) Organizational Climate Determinants of Resident Safety Culture in Nursing Homes. The Gerontologist, 51, 739-749. https://doi.org/10.1093/geront/gnr053

[11] Ross, J. (2011) Patient Safety Outcomes: the Importance of Understanding the Organizational Culture and Safety Climate. Journal of PeriAnesthesia Nursing, 26, 347-348. https://doi.org/10.1016/j.jopan.2011.08.001

[12] Sammer, C.E., Lykens, K., Singh, K.P., Mains, D.A. and Lackan, N.A. (2010) What Is Patient Safety Culture? A Review of the Literature. Journal of Nursing Scholarship, 42, 156-165. https://doi.org/10.1111/j.1547-5069.2009.01330.x

[13] Halligan, M. and Zecevic, A. (2011) Safety Culture in Healthcare: a Review of Concepts, Dimensions, Measures and Progress. BMJ Quality \& Safety, 20, 338-343. https://doi.org/10.1136/bmjqs.2010.040964

[14] Advisory Committee for the Safety of Nuclear Installations. Organising for Safety. In. Sheffield: HSE Books: Human Factors Study Group Third Report. 1993

[15] European Union Network for Quality in Health Care (2006) Use of Patient Safety Culture Instrument and Recommendations. European Network for Quality in Health Care, Office for Quality Indicators.

http://www.pasq.eu/DesktopModules/BlinkQuestionnaires/QFiles/448_WP4_REPO RT\%20\%20Use\%20of\%20\%20PSCI\%20and\%20recommandations\%20-\%20March\% 20\%202010.pdf

[16] Harrington, C., Choiniere, J., Goldmann, M., Fadnes Jacobsen, F., Lloyd, L., McGregor, M., Stamatopoulos, V. and Szebehely, M. (2012) Nursing Home Staffing Standards and Staffing Levels in Six Countries. Journal of Nursing Scholarship, 44, 88-98. https://doi.org/10.1111/j.1547-5069.2011.01430.x

[17] Sorra, J., Gray, L., Famolaro, T., Sorra, J., Yount, N. and Behm, J. (2016) Nursing Home Survey on Patient Safety Culture. Prepared by Westat, under Contract No. 
HHSA290201300003C, AHRQ Publication No. 15(16)-0052-EF, AHRQ Publication No. 15(16)-0052-EF (replaces 08(09)-0060).

https://www.ahrq.gov/sites/default/files/wysiwyg/professionals/quality-patient-safet y/patientsafetyculture/nursing-home/nhguide/nhguide.pdf

[18] Hedskold, M., Pukk-Harenstam, K., Berg, E., Lindh, M., Soop, M., Ovretveit, J. and Sachs, M.A. (2013) Psychometric Properties of the Hospital Survey on Patient Safety culture, HSOPSC, Applied on a Large Swedish Health Care Sample. BMC Health Services Research, 13, 332. https://doi.org/10.1186/1472-6963-13-332

[19] Castle, N.G., Wagner, L.M., Perera, S., Ferguson, J.C. and Handler, S.M. (2010) Assessing Resident Safety Culture in Nursing Homes: Using the Nursing Home Survey on Resident Safety. Journal of Patient Safety, 6, 59-67.

https://doi.org/10.1097/PTS.0b013e3181bc05fc

[20] Castle, N.G., Wagner, L.M., Ferguson, J.C. and Handler, S.M. (2011) Safety Culture of Nursing Homes: Opinions of Top Managers. Health Care Management Review, 36, 175-187. https://doi.org/10.1097/HMR.0b013e3182080d5f

[21] Cappelen, K., Aase, K., Storm, M., Hetland, J. and Harris, A. (2016). Psychometric Properties of the Nursing Home Survey on Patient Safety Culture in Norwegian Nursing Homes. BMC Health Services Research, 16, 446.

https://doi.org/10.1186/s12913-016-1706-x

[22] Ministry of Health and Care Services, Helse-og omsorgstjenesteloven https://lovdata.no/dokument/NL/lov/2011-06-24-30\#KAPITTEL_3

[23] The Coordination Reform (2008-2009) Proper Treatment-At the Right Place and Right Time. Report No. 47 (2008-2009) to the Storting.

https://www.regjeringen.no/contentassets/d4f0e16ad32e4bbd8d8ab5c21445a5dc/en$\mathrm{gb} / \mathrm{pdfs} / \mathrm{stm} 200820090047000 \mathrm{en} \_$pdfs.pdf

[24] National Norwegian Patient Safety Program. http://www.pasientsikkerhetsprogrammet.no

[25] Castle, N.G, Wagner, L.M., Perera, S., Ferguson, J.C. and Handler, S.M. (2011) Comparing the Safety Culture of Nursing Homes and Hospitals. Journal of Applied Gerontology, 30, 22-43. https://doi.org/10.1177/0733464809353603

[26] Kristensen, S., Christensen, K.B., Jaquet, A., Møller Beck, C., Sabroe, S., Bartels, P. and Mainz, J. (2016) Strengthening Leadership as a Catalyst for Enhanced Patient Safety Culture: A Repeated Cross-Sectional Experimental Study. BMJ Open, 6, 1-10. https://doi.org/10.1136/bmjopen-2015-010180

[27] Sorra, J., Famolaro, T., Yount, N., Burns, W., Liu, H. and Shyy, M. (2014) Nursing Home Survey on Patient Safety Culture 2014 User Comparative Database Report (Prepared by Westat, Rockville, M.D., under Contract No. HHSA290201300003C). Agency for Healthcare Research and Quality; November 2014, AHRQ Publication No. 15-0004.

https://www.ahrq.gov/sites/default/files/wysiwyg/professionals/quality-patient-safet y/patientsafetyculture/nursing-home/2014/nhsurv14-ptI.pdf

[28] Famolaro, T., Yount, N., Greene, K., Hare, R., Thornton, S. and Sorra, J. (2016) Nursing Home Survey on Patient Safety Culture 2016 User Comparative Database Report (Prepared by Westat, R., Rockville, M.D., under Contract No. HHSA 290201300003C). Agency for Healthcare Research and Quality; October 2016, AHRQ Publication No. 17-0004-EF.

https://www.ahrq.gov/sites/default/files/wysiwyg/professionals/quality-patient-safet y/patientsafetyculture/nursing-home/2016/nhsurv16-pt1.pdf

[29] The Working Environment Act (2007). 
http://www.arbeidstilsynet.no/binfil/download2.php?tid=92156

[30] Gautun, H. and Syse, A. (2013-2014) The Coordination Reform. How do Community Health Services Receive the Increased Amount of Patients Submitted from Hospitals? NOVA-Norwegian Social Research 2013. In: Report Oslo, NOVANorwegian Social Research 2013-2014. [In Norwegian] http://www.hioa.no/Om-HiOA/Senter-for-velferds-og-arbeidslivsforskning/NOVA /Publikasjonar/Rapporter/2013/Samhandlingsreformen

[31] Bratt, C. and Gautun, H. (2015) National Norms for Staffing in Nursing Homes. Tidsskrift for omsorgsforskning, 1, 99-107.

[32] Gandhi, T.K., Berwick, D.M. and Shojania, K.G. (2016) Patient Safety at the Crossroads. JAMA, 315, 1829-1830. https://doi.org/10.1001/jama.2016.1759

Submit or recommend next manuscript to SCIRP and we will provide best service for you:

Accepting pre-submission inquiries through Email, Facebook, LinkedIn, Twitter, etc. A wide selection of journals (inclusive of 9 subjects, more than 200 journals) Providing 24-hour high-quality service User-friendly online submission system Fair and swift peer-review system Efficient typesetting and proofreading procedure Display of the result of downloads and visits, as well as the number of cited articles Maximum dissemination of your research work

Submit your manuscript at: http://papersubmission.scirp.org/

Or contact ojn@scirp.org 